\title{
A New Fractional-Order Based Intelligent Maximum Power Point Tracking Control Algorithm for Photovoltaic Power Systems
}

\author{
Kuo-Nan Yu, Chih-Kang Liao, and Her-Terng Yau \\ Department of Electrical Engineering, National Chin-Yi University of Technology, Taichung 41170, Taiwan \\ Correspondence should be addressed to Her-Terng Yau; pan1012@ms52.hinet.net
}

Received 24 July 2014; Revised 15 December 2014; Accepted 26 December 2014

Academic Editor: Marcelo C. Cavalcanti

Copyright (c) 2015 Kuo-Nan Yu et al. This is an open access article distributed under the Creative Commons Attribution License, which permits unrestricted use, distribution, and reproduction in any medium, provided the original work is properly cited.

This paper proposes a new type of variable fractional-order incremental conductance algorithm (VFOINC), combined with extenics variable step size (EVSS) control into the maximum power point tracking (MPPT) design for photovoltaic power systems. At the beginning of maximum power tracking, the fractional-order number $\alpha$ is selected as 1; the good transient tracking characteristic of traditional incremental conductance method is used. When the maximum power point is approached, the fractional-order number $\alpha$ is selected as variable fractional order; the curve profile of $\alpha$ in fractional order is used to approximate, so that the system has good tracking effect in transient and steady states. The experimental and simulation results show that, compared with traditional incremental conductance method (INC) and fractional-order incremental conductance method (FOINC), this method has better MPPT effect.

\section{Introduction}

The green energy, including solar energy, wind energy, tide, and geothermal heat, has attracted considerable attention in recent years. Among those, solar energy is one of the cleanest energy sources as the solar radiant energy is converted into electric energy directly [1-5]. The present photovoltaic power systems have low conversion efficiency and high cost, and the power benefit varies with the climatic conditions and ambient temperature. There are some difficulties to be overcome. Due to nonlinearity of the power and voltage of photovoltaic power systems, how to use the MPPT to maximize the output efficiency of photovoltaic power systems in any climatic conditions becomes an important issue.

In actual physical system, many phenomena reflect fractional-order behavior, such as heat transfer and electromagnetic wave in solid [6]. The solar cell is a sort of semiconductor material (single crystalline silicon); the characteristic when the power generated by photocurrent crosses P-N junction (energy gap) reflects the nonlinear characteristic of photovoltage and photocurrent. The interaction between the diffusion current and drift current of semiconductor and the ambient temperature can be described by fractional order [7].

Many MPPT technologies have been implemented in photovoltaic power systems in previous literatures, such as voltage feedback method, power feedback method, INC [810], and perturbation and observation ( $\mathrm{P} \& \mathrm{O})$ [11-16]. This paper proposes combining VFOINC with EVSS [17] for tracking the maximum power point. In terms of the selection of derivative order number $\alpha$, at the beginning of maximum power tracking, $\alpha$ is selected as 1; the good transient tracking characteristic of INC is used. When the maximum power point is approached, $\alpha$ is selected as variable fractional order; the curve profile of $\alpha$ in fractional order is used to approximate, so that the system has good tracking effect in transient and steady states. The experimental and simulation results show that the VFOINC + EVSS method proposed in this paper uses DC/DC boost converter to adjust the duty cycle; compared with the INC and FOINC, the VFOINC + EVSS proposed in this paper can shorten the time for 


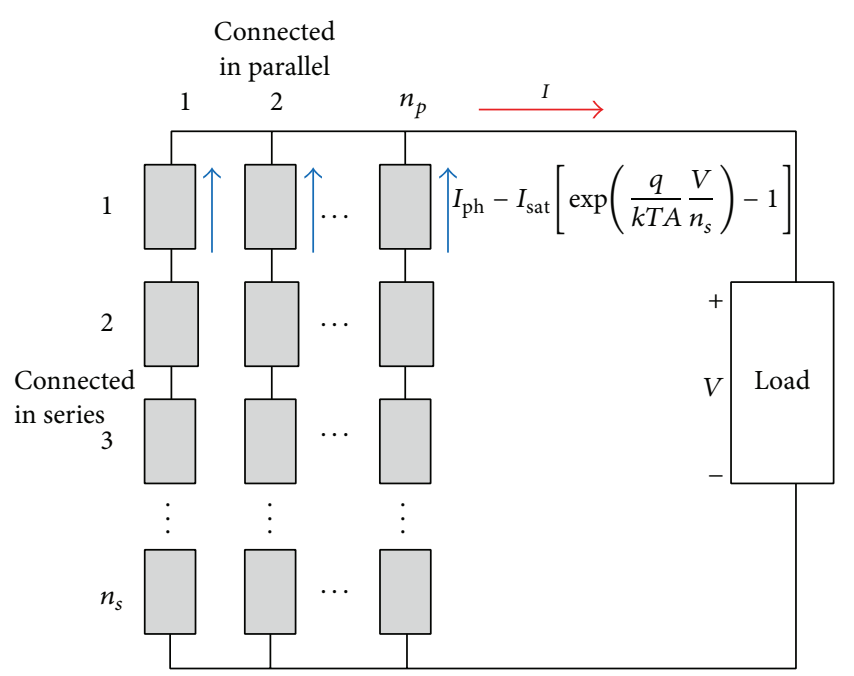

FIGURE 1: Internal equivalent diagram of photovoltaic panel.

MPPT, so that the efficiency of photovoltaic power systems is increased.

\section{Brief Introduction to Photovoltaic Power Systems}

The solar cell is P-N junction semiconductor structure converting solar energy into electric energy. The photovoltaic panel is composed of many solar cells connected in parallel and in series, as shown in Figure 1. The current be expressed as

$$
I=n_{p} I_{\mathrm{ph}}-n_{p} I_{\mathrm{sat}}\left[\exp \left(\frac{q}{k T A} \frac{V}{n_{s}}\right)-1\right],
$$

where $I$ is the output current of photovoltaic panel, $V$ is the output voltage of photovoltaic panel, $q$ is the electric quantity of electron, $I_{\mathrm{ph}}$ is the current, $I_{\text {sat }}$ is the reverse saturation current, $T$ is the battery temperature, $n_{p}$ is the parallel number of photovoltaic panels, $n_{s}$ is the serial number of photovoltaic panels, $k$ is the Boltzmann constant, and $A$ is the ideal factor coefficient of P-N junction. $I_{\text {sat }}$ is sensitive to the temperature, expressed as

$$
\begin{gathered}
I_{\mathrm{sat}}=I_{r}\left[\frac{T}{T_{r}}\right]^{3} \exp \left(\frac{q E_{G}}{k A}\left[\frac{1}{T_{r}}-\frac{1}{T}\right]\right) \\
I_{\mathrm{ph}}=\left[I_{\mathrm{sc}}+k_{\mathrm{sc}}\left(T-T_{r}\right)\right] \frac{S}{1000},
\end{gathered}
$$

where $T_{r}$ is the reference temperature at ordinary temperature $\left(25^{\circ} \mathrm{C}\right), I_{r}$ is the reverse saturation current of semiconductor at ordinary temperature, $E_{G}$ is the energy in energy gap, $I_{\mathrm{sc}}$ is the short-circuit current of semiconductor at ordinary temperature, $k_{\mathrm{sc}}$ is the temperature coefficient of shortcircuit current, and $S$ is the irradiance. The output power of photovoltaic power system can be represented by $P=$ $V I$; the power-voltage $(P-V)$ curve and voltage-current $(I-V)$ characteristic curve of photovoltaic power system are shown in Figure 2.
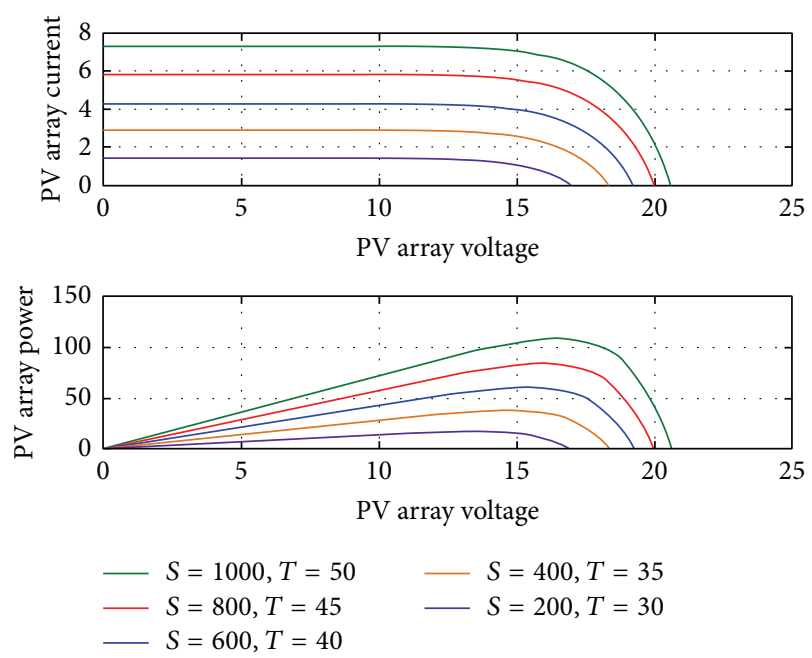

Figure 2: $P-V$ curve and $I-V$ curve of photovoltaic power system.

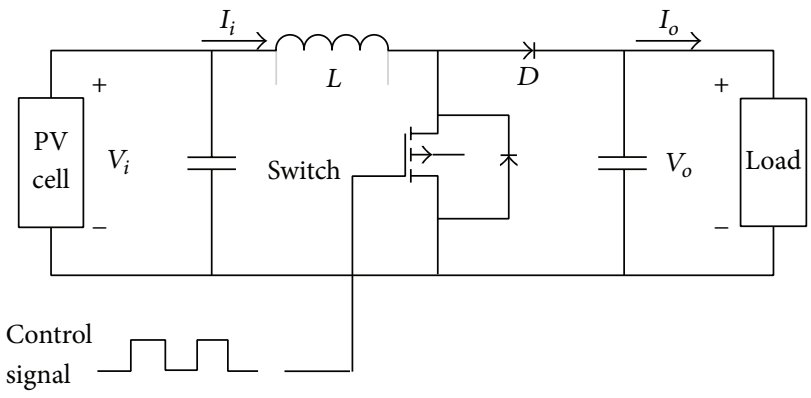

FIGURE 3: Boost-converter equivalent circuit diagram.

The MPPT is carried out in order to reach the peak point of nonlinear curve, the photovoltaic power system is connected to a boost converter, and the duty cycle of switch is controlled by the voltage and current generated by photovoltaic power system, so as to implement MPPT. The basic structure diagram [11-16] of the converter is shown in Figure 3. When the switch is "on", the photovoltaic power system charges the inductor via the switch. When the switch is "off," the photovoltaic power system releases the inductive energy to the load via diode. Adjusting the duty cycle changes input voltage and current, so as to change the output voltage and current. When the switch is off $t_{\text {on }}$ and on $t_{\text {off }}$, the current through the inductor can be expressed as

$$
\begin{gathered}
\text { Switch off } t_{\text {on }}: \Delta I_{L}{ }^{+}=\frac{V_{i}}{L} t_{\text {on }}, \\
\text { Switch on } t_{\text {off }}: \Delta I_{L}{ }^{-}=\frac{V_{i}-V_{o}}{L} t_{\text {off }} \text {. }
\end{gathered}
$$

The duty ratio $(D)$ of control switch is

$$
D=\frac{t_{\text {on }}}{t_{\text {on }}+t_{\text {off }}}=\frac{t_{\text {on }}}{T_{d}} .
$$




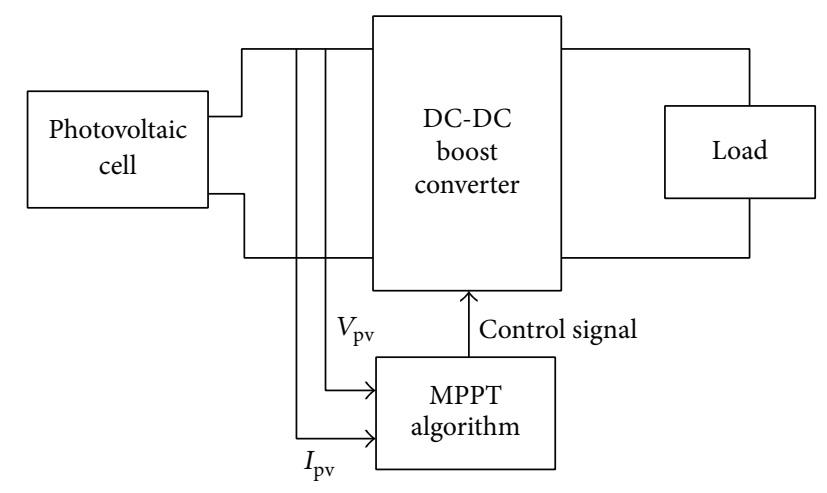

FIGURE 4: Structure diagram of photovoltaic power system.

As the one-cycle voltage variation of inductor is 0 , that is, $\Delta I_{L}{ }^{+}=\Delta I_{L}{ }^{-}$, the equation of output voltage $V_{o}$ can be obtained:

$$
V_{o}=V_{i} \frac{t_{\mathrm{on}}+t_{\mathrm{off}}}{t_{\mathrm{on}}}=\frac{V_{i}}{1-D} .
$$

Among multiple solar power system MPPT methods, the $\mathrm{P} \& \mathrm{O}$ is most extensively used [11-16] due to simple structure and few parameters required, and the parameters of characteristic curve of photovoltaic power system are not required. However, this method uses periodic perturbation, so there will be oscillation at the maximum power point, causing some unnecessary power loss. The INC is proposed in order to overcome this defect.

The INC is based on power-voltage $(P-V)$ curve of solar cell, meeting one of the following equations at maximum power point:

$$
\begin{gathered}
\frac{d P}{d V}=0, \\
\frac{d I}{d V} \approx-\frac{I-I_{o}}{V-V_{o}}=-\frac{\Delta I}{\Delta V},
\end{gathered}
$$

where $I_{o}$ and $V_{o}$ are the current and voltage captured at previous time point, respectively, and $\Delta I$ and $\Delta V$ are the current and voltage variations in unit time, respectively. However, in the process of MPPT, the magnitude of offset $\Delta V$ determines the speed of reaching MPP and the perturbation after the MPP is reached. The decision depends on the user. However, the VFOINC + EVSS [17] proposed in this paper can use the mathematical model in fractional-order form to describe the diffusion phenomenon of solar cell at different temperatures. In terms of MPPT speed, the EVSS is used to improve the tracking speed and the perturbation in steady state.

The photovoltaic power system architecture proposed in this paper is shown in Figure 4. The photovoltaic panel connects the output voltage and current to the DC-DC boost converter directly, and the MPPT is used to control signal and adjust the duty cycle of switching pulse width modulation (PWM). Finally, the DC-DC boost converter is connected to the load to measure the system output power.

\section{Design of Algorithm and Control Method}

This paper uses MATLAB R2010a Simulink to build the simulated photovoltaic power system architecture and to design the control method. Figure 5 shows the photovoltaic power system simulation built by this paper. The module FOINC can be replaced by different MPPTs for duty cycle control of different switching pulse adjustment control methods.

3.1. Fractional-Order Differentiator. The fractional-order differentiator is often applied to signal processing, adaptive control, active control, and linear and nonlinear feedback control. At present, many computing applications of fractional-order derivative have been proposed; according to the definition of Riemann-Liouville and Grunwald-Letnikov [18-20], general fractional-order differentiator can be expressed as

$$
D_{t}^{\alpha} t^{m} \approx \frac{\gamma(m+1)}{\gamma(m+1-\alpha)} t^{m-\alpha},
$$

where $\gamma()$ represents $\gamma$ function and $\alpha$ is the order number of derivative, when its value is $0<\alpha<1$, representing physical phenomenon of fractional order, for example, heat transfer and electromagnetic wave in solid [6]. The solar cell is a sort of semiconductor material (single crystalline silicon). The characteristic when the power generated by photocurrent crosses the P-N junction (energy gap) reflects the nonlinear characteristic of photovoltage and photocurrent. The interaction between the diffusion current and drift current of semiconductor and the ambient temperature can be described by fractional order.

3.2. Variable Fractional-Order Incremental Conductance Method. General fractional-order differentiator can be expressed as (8); when the INC is used, (7) can be expressed as

$$
\begin{gathered}
\frac{d^{\alpha} I}{d V^{\alpha}} \approx \lim _{\Delta V \rightarrow 0} \frac{I(V)-\alpha I(V-\Delta V)}{\Delta V^{\alpha}}, \\
\frac{d^{\alpha} I}{d V^{\alpha}} \approx \frac{I-\alpha I_{0}}{\left(V-V_{o}\right)^{\alpha}} .
\end{gathered}
$$

If $\alpha>0$, the geometric interpretation of fractional order can be represented as Figure 6. The slope is a straight line when $\alpha=1$, that is, general first derivative. Therefore, $0<\alpha<1$ presents the form of fractional-order derivative, approximately to curve form, referring to literature [21]. The result of using (8) in the right part of (7) is

$$
\begin{aligned}
\frac{d^{\alpha}}{d V^{\alpha}}\left(-\frac{I_{o}}{V_{o}}\right)= & \left(-\frac{1}{V_{o}}\right) \frac{d^{\alpha} I_{o}}{d V^{\alpha}}+\left(-I_{o}\right) \frac{d^{\alpha} V_{o}^{-1}}{d V^{\alpha}} \\
= & \left(-\frac{1}{V_{o}}\right)\left(\frac{\gamma(2)}{\gamma(2-\alpha)}\right)\left(I_{o}\right)^{1-\alpha} \\
& +\left(-I_{0}\right) \frac{\gamma(0)}{\gamma(-\alpha)} V_{o}^{-1-\alpha},
\end{aligned}
$$

where $\operatorname{res}(\gamma,-z)=(-1)^{z} / z !, z=0,-1,-2,-3, \ldots$, and $\gamma(0)=$ res $(\gamma, 0)$, and res represents the residue in complex plane. 


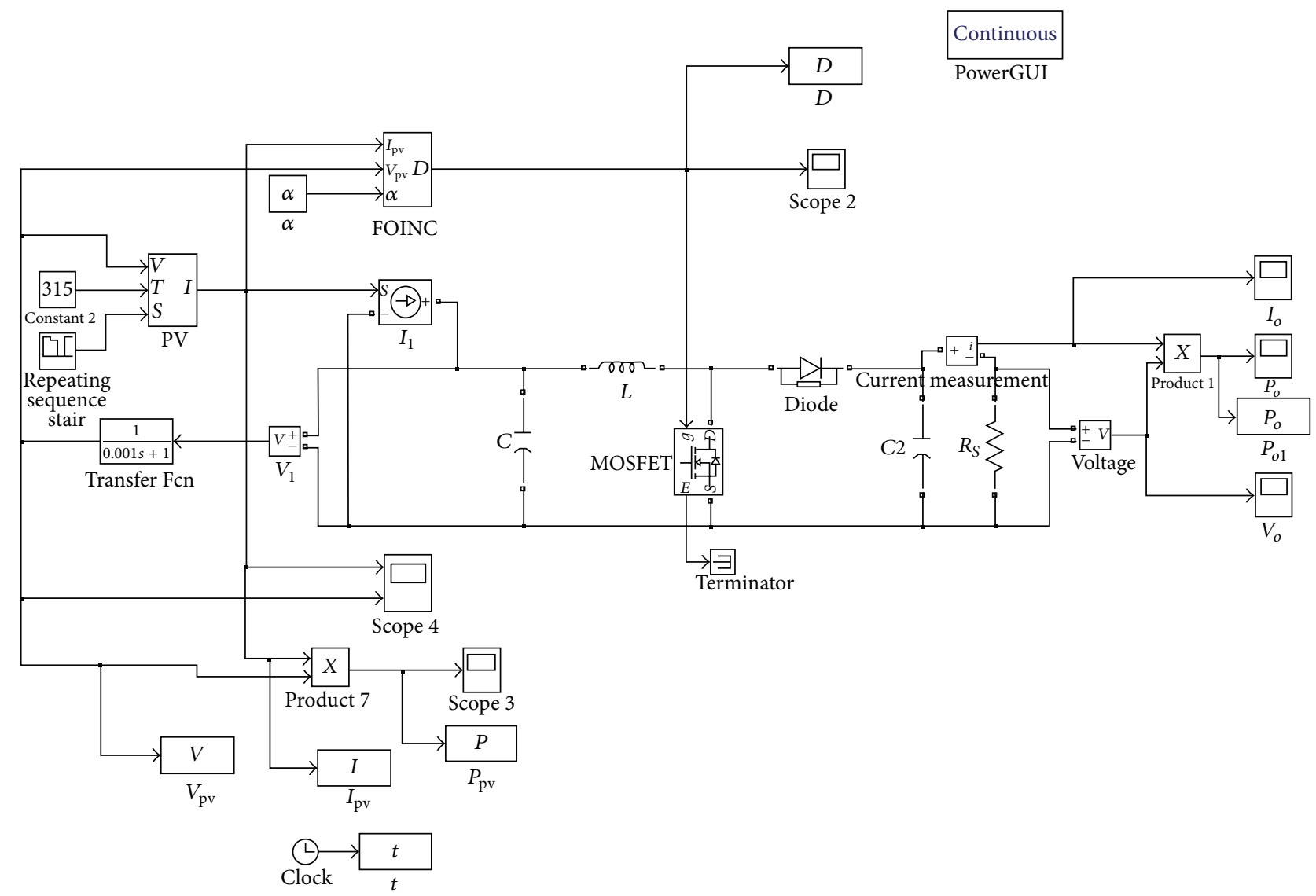

FIGURE 5: Simulated photovoltaic power system.

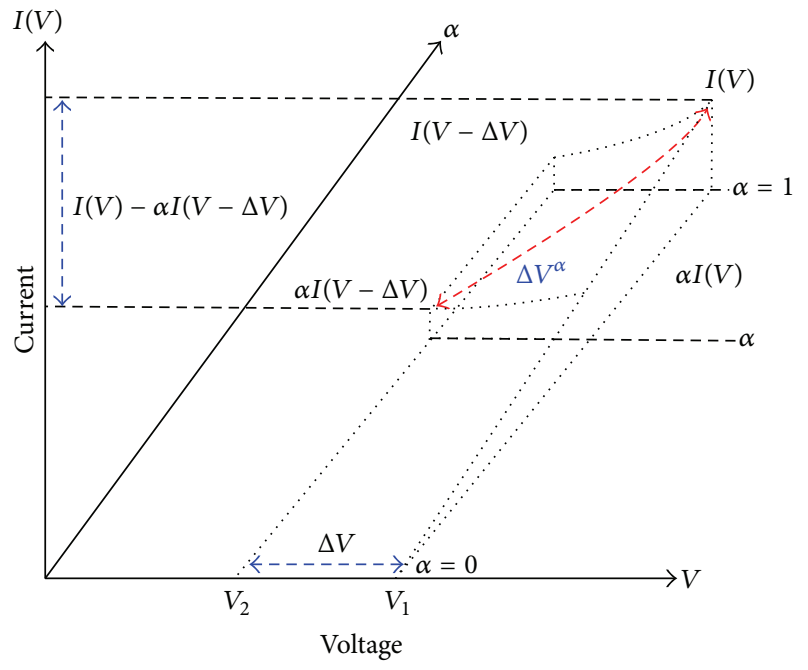

FIGURE 6: Geometric interpretation of $\Delta V$ in fractional-order differentiator.

As the traditional INC tracks maximum power fast and the curve of fractional-order differentiator INC nearby MPP approximates MPPT, the steady-state tracking effect is better than general INC. Therefore, this paper proposes using variable derivative value $\alpha$ in Figure 4 for calculation of MPPT.
It has good response to transient MPPT and steady-state MPP sweeping, so as to increase the overall efficiency of photovoltaic power system.

This paper uses voltage $V$ and current $I$ and power $P$ as calculated variance in captured signal, voltage, and current, $\Delta V=V-V_{o}, \Delta I=I-I_{o}$, and the slope is the slope $(\Delta P / \Delta V)$ of power-voltage curve of solar cell; the variation of partial voltage and current of fractional-order differentiator approximates as $d^{\alpha} I=I-\alpha I_{0}$ and $d V^{\alpha}=\left(V-V_{o}\right)^{\alpha}$. In terms of selection of derivative order number $\alpha$, at the beginning of MPPT, $\alpha$ is selected as 1; the good transient tracking characteristic of traditional INC is used. When the MPP is approached, $\alpha$ is selected as variable fractional-order form, and the curve profile of $\alpha$ in fractional order is used to approximate, so that the system has good tracking effect in transient and steady states.

3.3. Extenics Variable Step Size (EVSS). The offset $\Delta V$ during MPPT of traditional INC determines the tracking speed and the perturbation accuracy when the MPP is reached. In comparison to traditional MPPT algorithm, the variable step size control has gradually increased or decreased offset $\Delta V$ variable of step size, so as to improve the tracking speed and stability. For detailed variable step size control, please refer to [20]. 


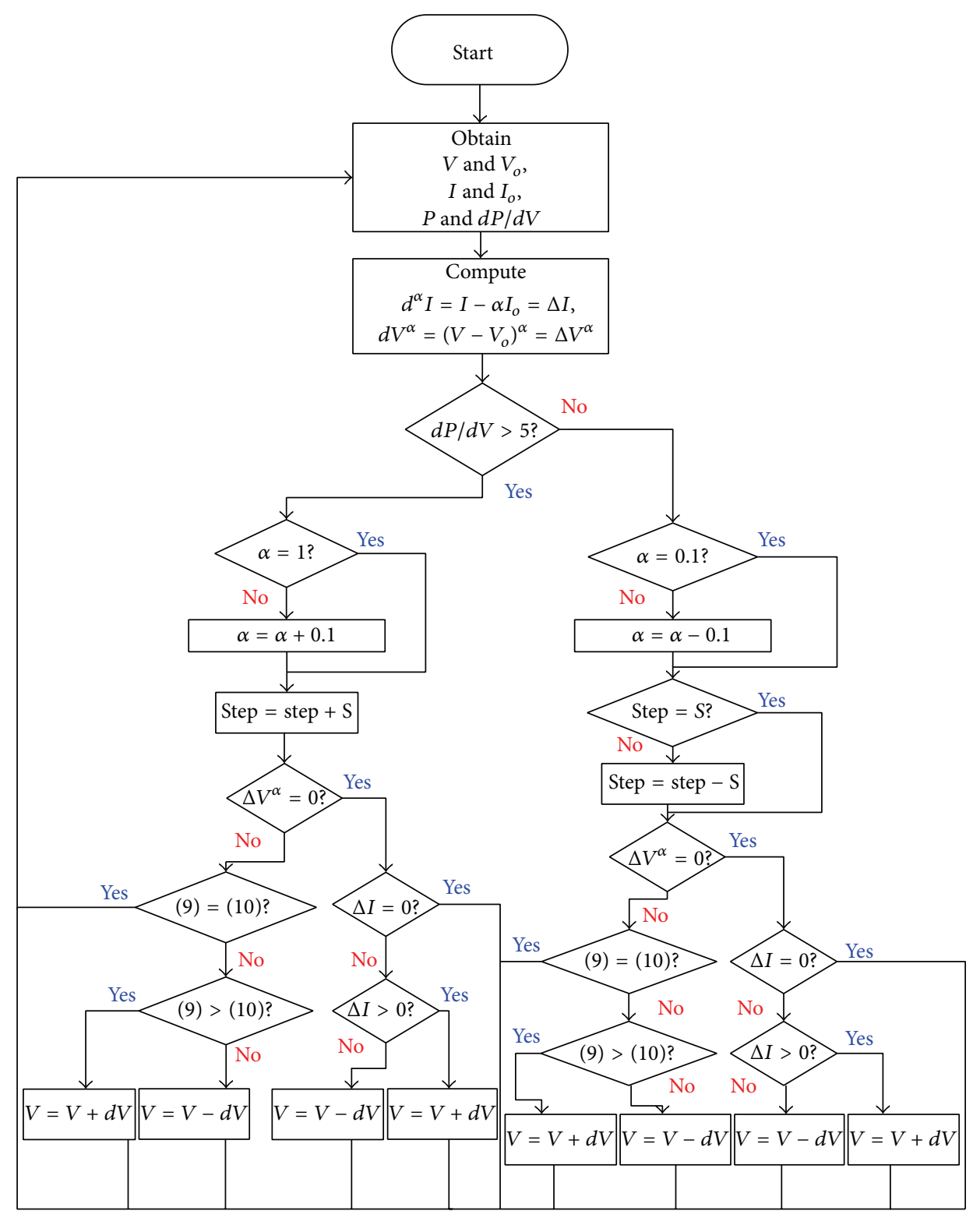

FIGURE 7: The control flow of VFOINC + EVSS.

As the variable step size control has variable step size nearby MPP, there will be voltage perturbation problem nearby MPP. Therefore, this paper proposes adding extenics theory in the variable step size control $[22,23]$ to deduce the EVSS. The voltage, power, and slope are captured as reference frame, so that the minimum step size can be used for perturbation nearby the MPP, increasing the efficiency of photovoltaic power system. The control flow of VFOINC + EVSS proposed in this paper is shown in Figure 7.

\section{Simulation Analysis Results and Comparison}

This paper uses MATLAB R2010a Simulink to build the model and controller of photovoltaic power system. This simulation is the comparison of different states of irradiance and temperature and step size. Figure 8 shows the curve test of photovoltaic power system at specific temperature and irradiance, including voltage-power $(P-V)$ curve, currentvoltage $(I-V)$ curve, duty ratio (cycle) $(D)$, and tracking number curves.

The first simulated condition is irradiance $1000 \mathrm{~kW} / \mathrm{m}^{2}$ and temperature $25^{\circ} \mathrm{C}$; the other condition is irradiance decreasing from $1000 \mathrm{~kW} / \mathrm{m}^{2}$ to $900 \mathrm{~kW} / \mathrm{m}^{2}$ and then decreasing to $200 \mathrm{~kW} / \mathrm{m}^{2}$ and increasing to $1000 \mathrm{~kW} / \mathrm{m}^{2}$, and the INC, FOINC, and VFOINC + EVSS are compared.

According to the simulation result in Figure 9, as the step size of INC depends on the user, the speed and accuracy are limited to some extent. However, in the same step size, the transient tracking speed of INC is better than FOINC. In terms of the combination of VFOINC and EVSS, Figure 10 shows the combination of good transient tracking efficiency 

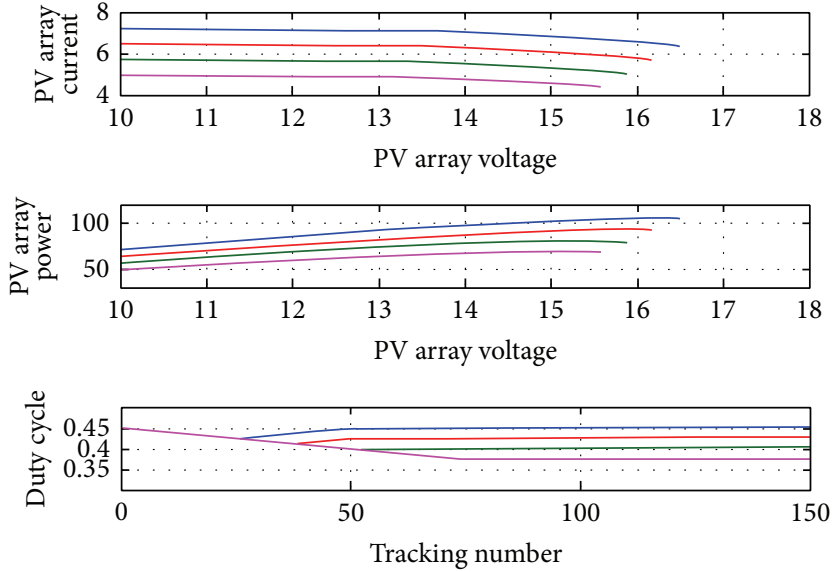

$\begin{array}{rlrl}T & =42, S=1000 \\ -T & =40, S=900 & -T & =38, S=800 \\ -T & =36, S=700\end{array}$

Figure 8: Curve test with specific temperature and irradiance.

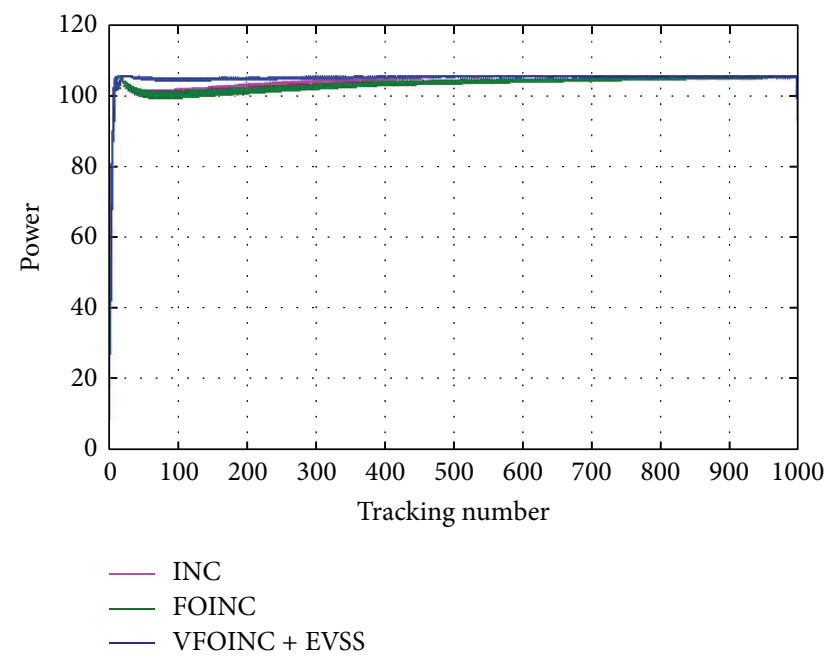

FIGURE 9: Comparison of INC and FOINC and VFOINC with EVSS (fixed irradiance).

of traditional INC and steady-state stability of VFOINC and EVSS; it is observed that the VFOINC + EVSS proposed in this paper has better MPPT simulation curve in transient and steady states.

The second simulated condition is the irradiance decreasing from $1000 \mathrm{~kW} / \mathrm{m}^{2}$ to $900 \mathrm{~kW} / \mathrm{m}^{2}$ and then decreasing to $200 \mathrm{~kW} / \mathrm{m}^{2}$ and increasing to $1000 \mathrm{~kW} / \mathrm{m}^{2}$, as shown in Figure 11. The INC, FOINC, and VFOINC + EVSS are compared. The variance in $\alpha$ is shown in Figure 12.

Figure 12 shows the variance in $\alpha$. It is observed that, at the start of simulation, as the system is just started up, letting $\alpha=1$ for tracking MPP, the form of INC is used for tracking; $\alpha$ is reduced to 0.1 gradually when MPP is approached, so that the system uses INC in transient state and uses VFOINC in steady state. In addition, in terms of $\alpha$ variation when the tracking number is 1000, 2000, and 3000, the MPP shifts as the irradiance changes; the system increases $\alpha$ value again to

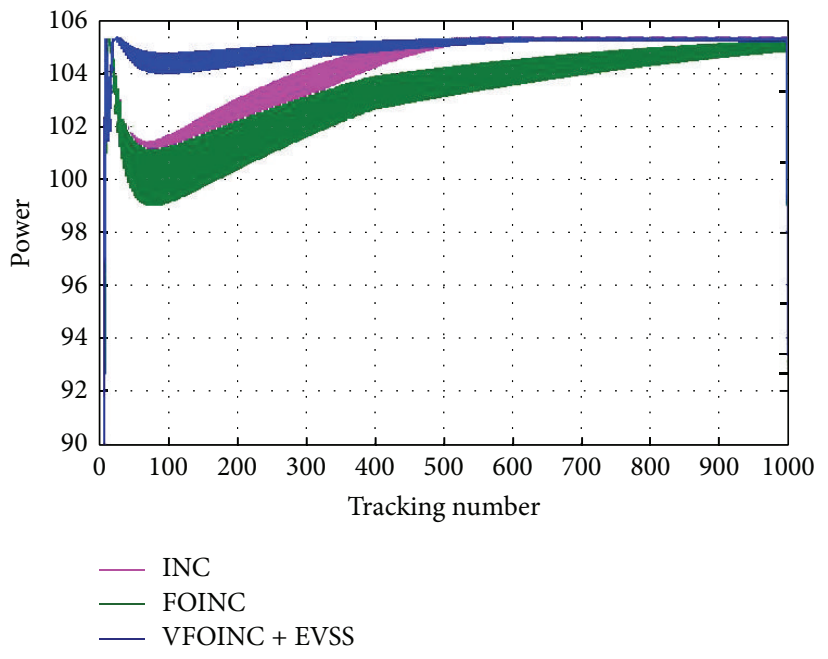

FIGURE 10: Comparison of INC and FOINC and VFOINC with EVSS (power regulated to 90-106 W) (fixed irradiance).

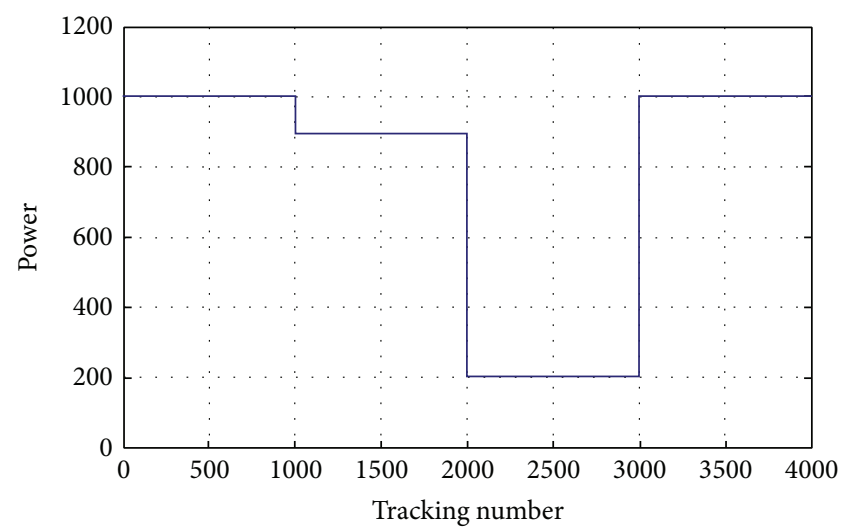

FIGURE 11: Step input variable irradiance.

increase the tracking speed and reduces it to 0.1 again when the MPP is approached, so that the transient and steady-state response curves have better effect.

Figure 13 shows the simulation result, and Figure 14 shows that the step size of INC still depends on the user; the speed and accuracy are limited to some extent, so that the MPPT always costs a long time in the case of variable irradiance, causing unnecessary power loss. The VFOINC + EVSS proposed in this paper can improve the excessive tracking number of traditional INC algorithm in the case of variable irradiance, so that the system has better curve.

\section{Experimental Results}

In order to show the efficiency of this scheme in real solar cell system, the performance of the proposed controller was evaluated experimentally and was compared with INC method and FOINC method. The specification of the experimental solar panel is shown in Table 1. Figure 15 shows the experimental results obtained for the output power given a uniform irradiance of $1000 \mathrm{~W} / \mathrm{m}^{2}$. From the results, it can 


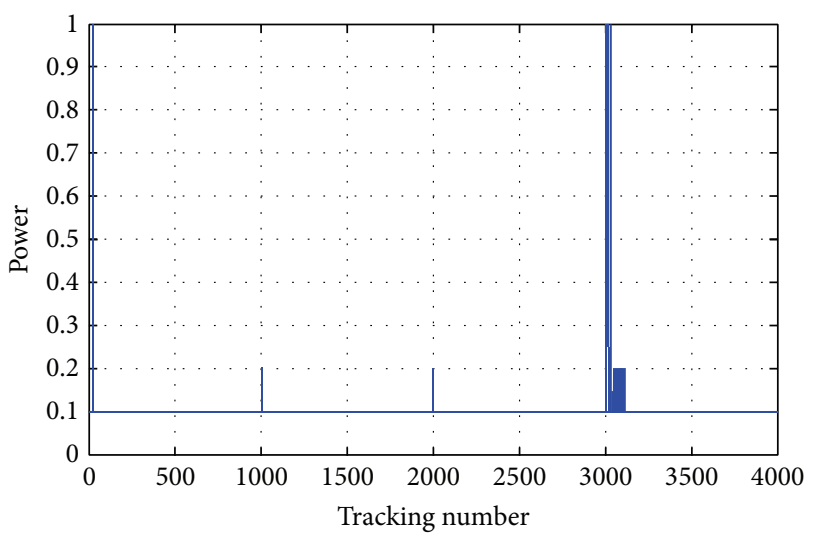

FIGURE 12: Variation of variable fractional-order differentiator $\alpha$.

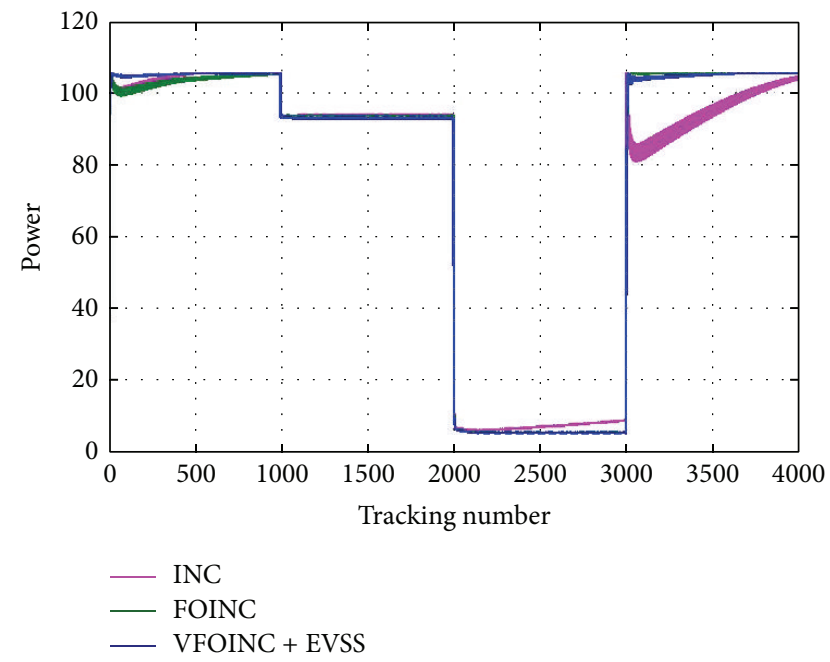

FIGURE 13: Comparison of INC and FOINC and VFOINC with EVSS (variable irradiance).

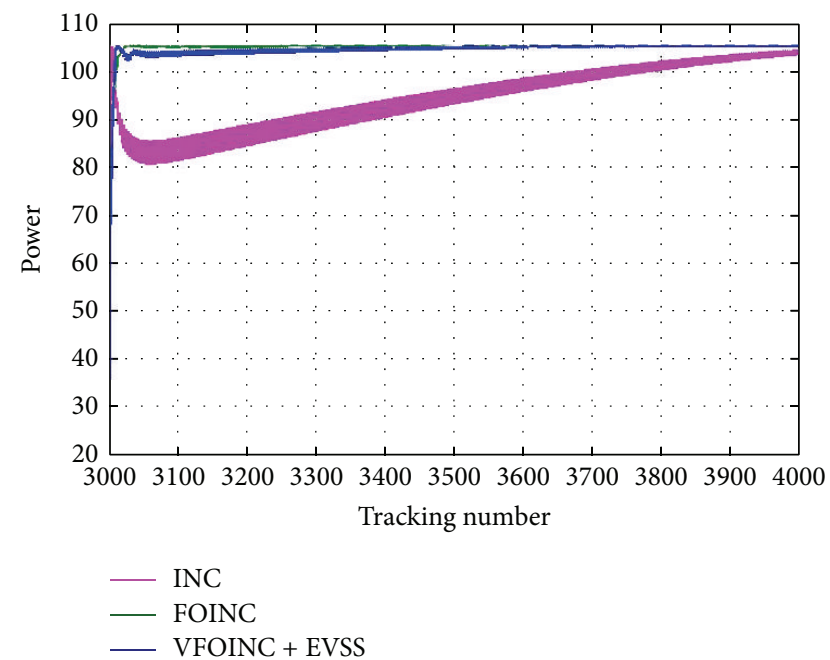

FIgURE 14: Comparison of INC and FOINC with VSS and VFOINC with EVSS (variable irradiance) (tracking number is 3000-4000).
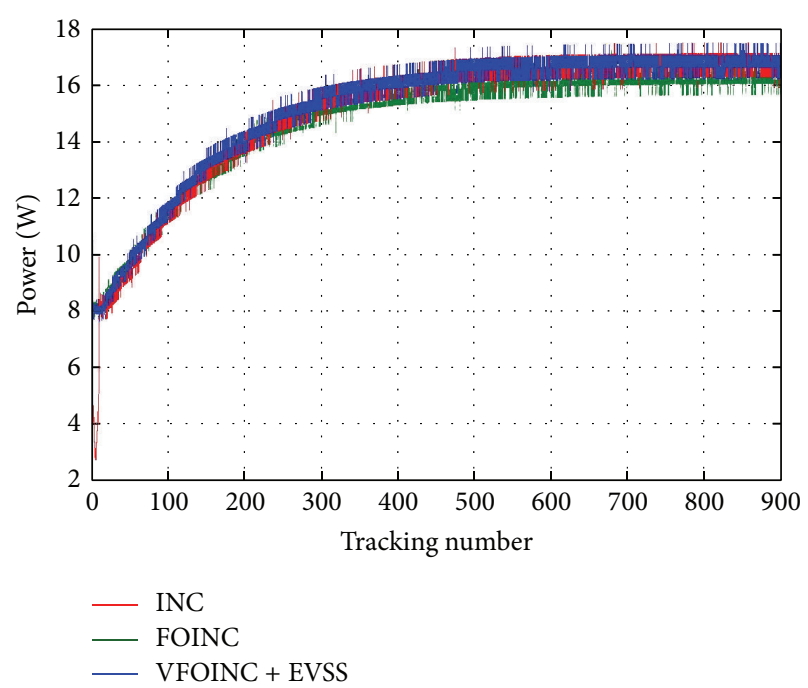

FIGURE 15: Experimental comparison of INC and FOINC with VSS and VFOINC with EVSS (fixed irradiance).

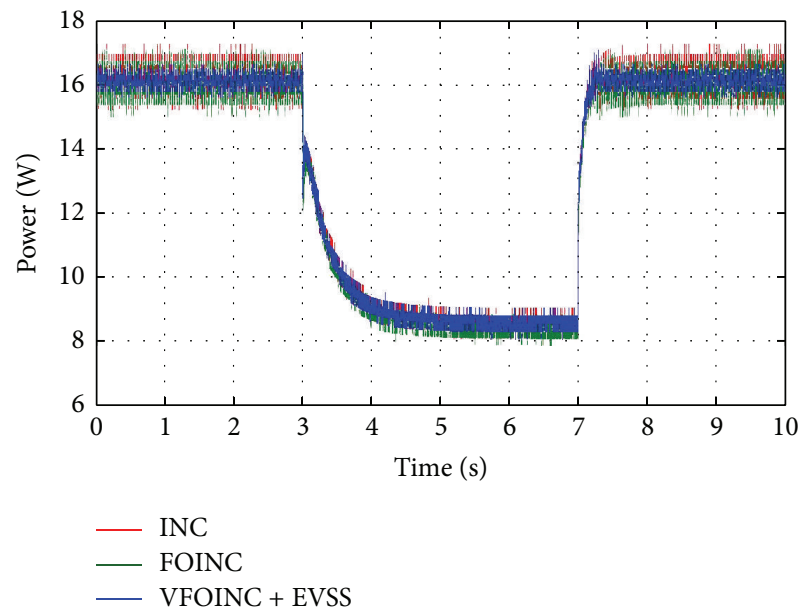

FIGURE 16: Experimental comparison of INC and FOINC and VFOINC with EVSS (variable irradiance).

TABLE 1: Specification of SYK17-18M solar panel.

\begin{tabular}{lcccc}
\hline$P_{\max }$ & $V_{\mathrm{MPP}}$ & $I_{\mathrm{MPP}}$ & $V_{\mathrm{OC}}$ & $I_{\mathrm{SC}}$ \\
\hline $17 \mathrm{~W}$ & $18 \mathrm{~V}$ & $0.94 \mathrm{~A}$ & $21.24 \mathrm{~V}$ & $1.04 \mathrm{~A}$ \\
\hline
\end{tabular}

be seen that VFOINC + EVSS has better tracking rates than traditional INC and in terms of the steady-state response it is also good and has the same effect. In order to show that this scheme is robust to the irradiance, the results of irradiances changed from $1000 \mathrm{~kW} / \mathrm{m}^{2}$ to $400 \mathrm{~kW} / \mathrm{m}^{2}$ and then increased to $1000 \mathrm{~kW} / \mathrm{m}^{2}$ as shown in Figure 16. Our results are also consistent with the results of the simulations. It can prove the feasibility of the proposed method.

\section{Conclusion}

This paper uses VFOINC + EVSS for photovoltaic power system MPPT control, to improve the MPPT speed and 
steady-state perturbation of INC. In terms of selection of derivative order number $\alpha$, at the start of MPPT, $\alpha$ is selected as 1; the good tracking characteristic of traditional INC in transient state is used. When the MPP is approximated, $\alpha$ is selected as variable fractional-order form; the curve profile of $\alpha$ in fractional order is used to approximate, so that the system has good tracking effect in transient and steady states. According to the simulation result of the algorithm, the transient and steady-state responses of the control method proposed in this study to photovoltaic MPPT system are better than those of INC and FOINC, meaning this method for MPPT can reduce unnecessary power loss of the system, so as to increase the generating efficiency of system.

\section{Conflict of Interests}

The authors declare that there is no conflict of interests regarding the publication of this paper.

\section{References}

[1] C. Hua, J. Lin, and C. Shen, "Implementation of a DSPcontrolled photovoltaic system with peak power tracking," IEEE Transactions on Industrial Electronics, vol. 45, no. 1, pp. 99-107, 1998.

[2] C. A. Otieno, G. N. Nyakoe, and C. W. Wekesa, "A neural fuzzy based maximum power point tracker for a photovoltaic system," in Proceedings of the IEEE AFRICON, 6, p. 1, Nairobi, Kenya, September 2009.

[3] J.-M. Kwon, B.-H. Kwon, and K.-H. Nam, "Grid-connected photovoltaic multistring PCS with PV current variation reduction control," IEEE Transactions on Industrial Electronics, vol. 56, no. 11, pp. 4381-4388, 2009.

[4] G. Petrone, G. Spagnuolo, R. Teodorescu, M. Veerachary, and M. Vitelli, "Reliability issues in photovoltaic power processing systems," IEEE Transactions on Industrial Electronics, vol. 55, no. 7, pp. 2569-2580, 2008.

[5] R.-J. Wai, W.-H. Wang, and C.-Y. Lin, "High-performance stand-alone photovoltaic generation system," IEEE Transactions on Industrial Electronics, vol. 55, no. 1, pp. 240-250, 2008.

[6] C. Hwang, J.-F. Leu, and S.-Y. Tsay, "A note on time-domain simulation of feedback fractional-order systems," IEEE Transactions on Automatic Control, vol. 47, no. 4, pp. 625-631, 2002.

[7] C.-H. Lin, C.-H. Huang, Y.-C. Du, and J.-L. Chen, "Maximum photovoltaic power tracking for the PV array using the fractional-order incremental conductance method," Applied Energy, vol. 88, no. 12, pp. 4840-4847, 2011.

[8] K. H. Hussein, I. Muta, T. Hoshino, and M. Osakada, "Maximum photovoltaic power tracking: an algorithm for rapidly changing atmospheric conditions," IEE Proceedings: Generation, Transmission and Distribution, vol. 142, no. 1, pp. 59-64, 1995.

[9] J.-M. Kwon, K.-H. Nam, and B.-H. Kwon, "Photovoltaic power conditioning system with line connection," IEEE Transactions on Industrial Electronics, vol. 53, no. 4, pp. 1048-1054, 2006.

[10] X. Zhou, D. Song, Y. Ma, and D. Cheng, "The simulation and design for MPPT of PV system based on incremental conductance method," in Proceedings of the WASE International Conference on Information Engineering (ICIE '10), pp. 314-317, Hebei, China, August 2010.

[11] A. J. Mahdi, W. H. Tang, and Q. H. Wu, "Estimation of tip speed ratio using an adaptive perturbation and observation method for wind turbine generator systems," in Proceedings of the IET Conference on Renewable Power Generation, pp. 1-6, September 2011.

[12] N. Femia, G. Petrone, G. Spagnuolo, and M. Vitelli, "A technique for improving P\&O MPPT performances of double-stage gridconnected photovoltaic systems," IEEE Transactions on Industrial Electronics, vol. 56, no. 11, pp. 4473-4482, 2009.

[13] A. I. Bratcu, I. Munteanu, S. Bacha, D. Picault, and B. Raison, "Cascaded DC-DC converter photovoltaic systems: power optimization issues," IEEE Transactions on Industrial Electronics, vol. 58, no. 2, pp. 403-411, 2011.

[14] E. J. Estébanez, V. M. Moreno, A. Pigazo, M. Liserre, and A. Dell'Aquila, "Performance evaluation of active islanding-detection algorithms in distributed-generation photovoltaic systems: two inverters case," IEEE Transactions on Industrial Electronics, vol. 58, no. 4, pp. 1185-1193, 2011.

[15] C. Cecati, F. Ciancetta, and P. Siano, "A multilevel inverter for photovoltaic systems with fuzzy logic control," IEEE Transactions on Industrial Electronics, vol. 57, no. 12, pp. 4115-4125, 2010.

[16] N. Femia, G. Petrone, G. Spagnuolo, and M. Vitelli, “Optimization of perturb and observe maximum power point tracking method," IEEE Transactions on Power Electronics, vol. 20, no. 4, pp. 963-972, 2005.

[17] J. Li and H. Wang, "A novel stand-alone PV generation system based on variable step size INC MPPT and SVPWM control," in Proceedings of the IEEE 6th International Power Electronics and Motion Control Conference (IPEMC '09), pp. 2155-2160, May 2009.

[18] I. Podlubny, Fractional Differential Equations, vol. 198 of Mathematics in Science and Engineering, Academic Press, New York, NY, USA, 1999.

[19] C. Ma and Y. Hori, "Fractional-order control: theory and applications in motion control," IEEE Industrial Electronics Magazine, vol. 1, no. 4, pp. 6-16, 2007.

[20] S. K. Kenneth and R. Bertram, An Introduction to the Fractional Calculus and Fractional Differential Equations, John Wiley \& Sons, New York, NY, USA, 1993.

[21] S. Das, Functional Fractional Calculus for System Identification and Controls, Springer, Berlin, Germany, 2008.

[22] W. Chen and R. Chen, "The evaluation of scientific journals in Chinese Scientific Research based on extenics theory," in Proceedings of the International Conference on Information Management, Innovation Management and Industrial Engineering, pp. 195-198, October 2012.

[23] S. Hong-Chun, H. Ze-Jiang, S. Shi-Yun, and Y. Qing, "The fault diagnosis algorithm for transformer based on Extenics and rough set theory," in Proceedings of the 3rd International Conference on Electric Utility Deregulation and Restructuring and Power Technologies (DRPT '08), pp. 1269-1272, Nanjing, China, April 2008. 

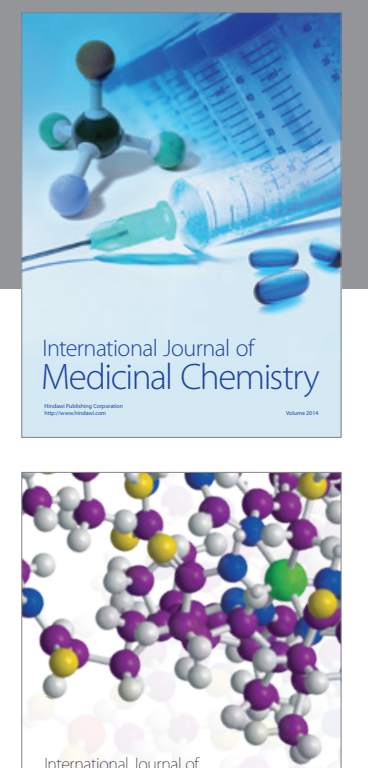

\section{Carbohydrate} Chemistry

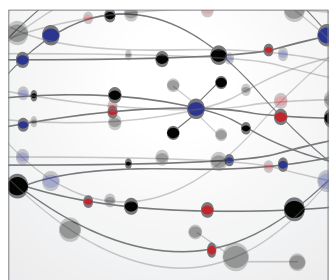

The Scientific World Journal
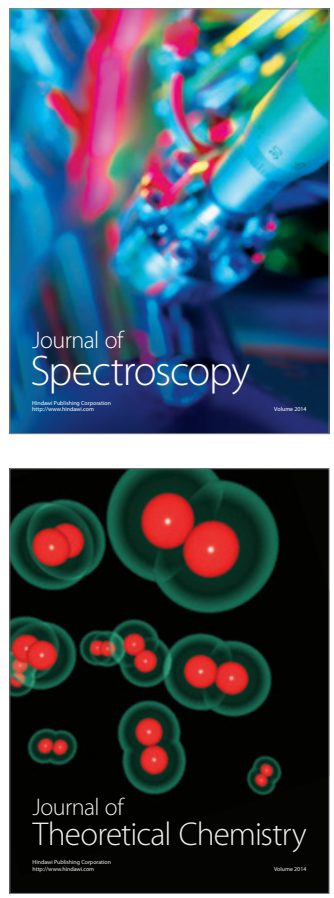
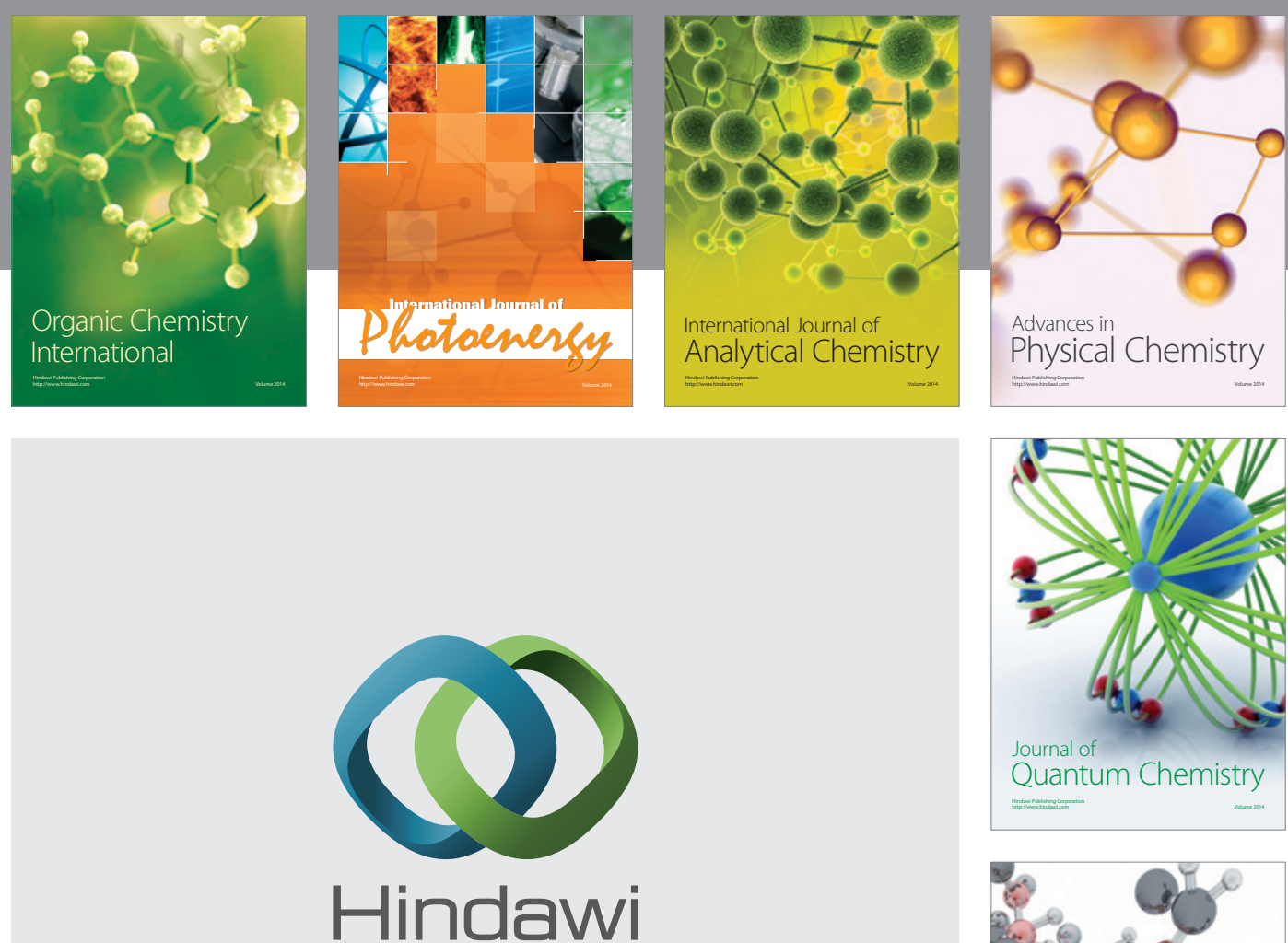

Submit your manuscripts at

http://www.hindawi.com

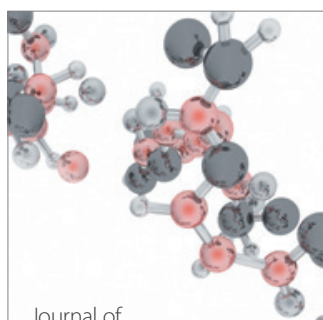

Analytical Methods

in Chemistry

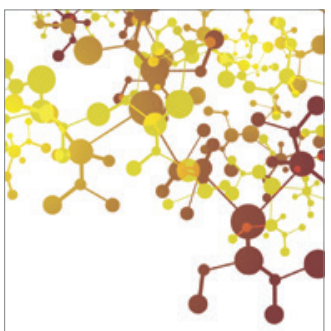

Journal of

Applied Chemistry

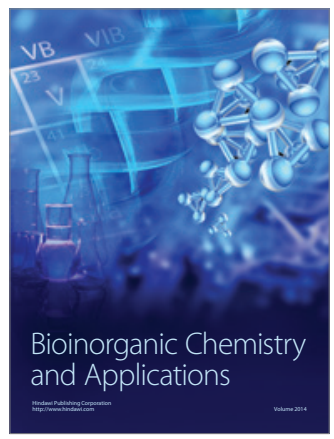

Inorganic Chemistry
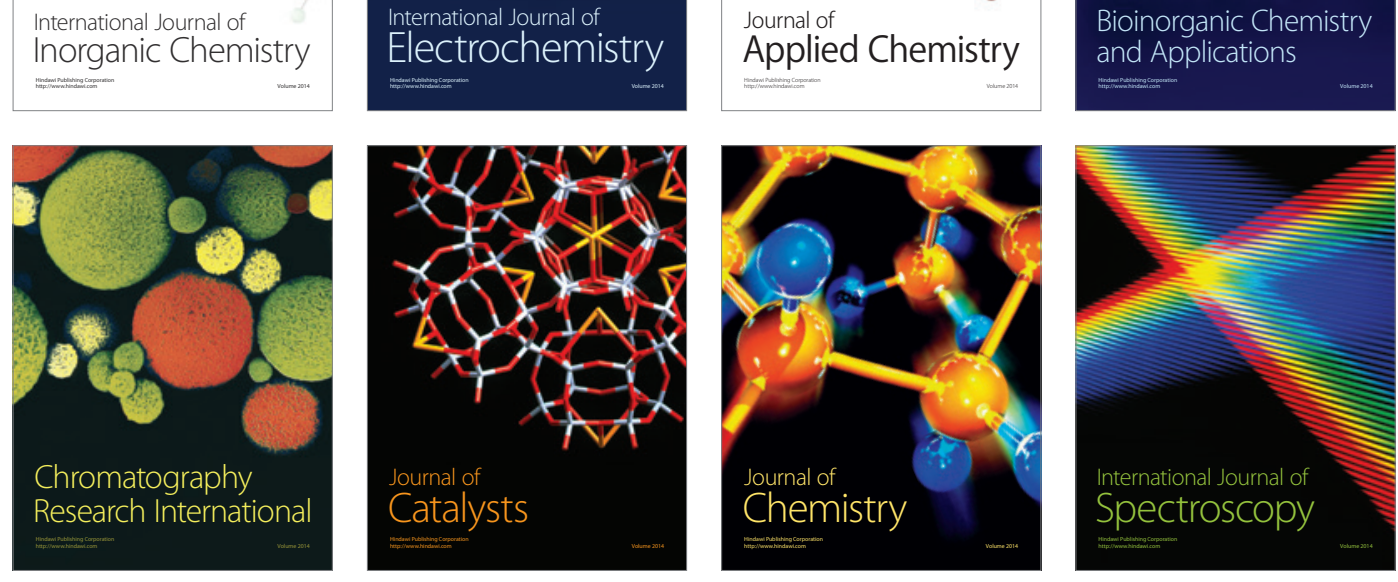